\title{
Anti-angiogenic effects of the water extract of HangAmDan (WEHAD), a Korean traditional medicine
}

\author{
BANG Ji-Young $^{1 \dagger}{ }^{\dagger}$, KIM Kyung-Soon $^{4 \dagger}$, KIM Eung-Yoon $^{1}$, YOO Hwa-Seung ${ }^{4}$, \\ LEE Yeon-Weol ${ }^{4}$, CHO Chong-Kwan ${ }^{4}$, CHOI YoungJin ${ }^{3}$, \\ JEONG Hyun-Ja ${ }^{3} \&$ KANG In-Cheol ${ }^{1,2,3 *}$ \\ ${ }^{1}$ InnoPharmasceen Inc., Hoseo University, Asan 336-795, Republic of Korea, \\ ${ }^{2}$ Department of Biological Science, College of Natural Science, Hoseo University, Asan 336-795, Republic of Korea; \\ ${ }^{3}$ BioChip Research Center, Hoseo University, Asan 336-795, Republic of Korea; \\ ${ }^{4}$ East-West Cancer Center, Dunsan Oriental Medical Hospital of Daejeon University, Daejeon 302-122, Republic of Korea
}

Received August 23, 2010; accepted December 29, 2010

\begin{abstract}
We investigated the anti-angiogenic effects of the water extract of HangAmDan (WEHAD), which is a crude extract of nine Korean medicinal substances of animal and plant origin. In human umbilical vein endothelial cells, WEHAD significantly inhibited bFGF-induced proliferation, adhesion, migration, and capillary tube formation. We used an antibody array to perform an analysis of signaling proteins, which showed up-regulated expression of various proteins including RAD51, RAD52, and p73, and down-regulated expression of pFAK. Blood vessel formation in a chick chorioallantoic membrane (CAM) treated with WEHAD was markedly reduced in length compared with a PBS-treated control group. These results suggest that inhibition of angiogenesis by WEHAD may be the mechanism of action for the anti-cancer effects of HAD.
\end{abstract}

angiogenesis, HangAmDan, WEHAD, antibody array, HUVEC

Citation: Bang J Y, Kim K S, Kim E Y, et al. Anti-angiogenic effects of the water extract of HangAmDan (WEHAD), a Korean traditional medicine. Sci China Life Sci, 2011, 54: 248-254, doi: 10.1007/s11427-011-4144-3

Angiogenesis, which is the formation of new blood vessels from existing endothelium, is an essential process in various physiological and pathological situations including wound repair, organ regeneration, embryonic vascular system development and tumorigenesis. Tumor growth and metastasis are highly dependent on angiogenesis [1,2]. Treatments for human cancer that inhibit angiogenesis are the subject of intensive clinical investigation and, therefore, better understanding of the fundamental mechanisms of angiogenesis is critical in developing and improving these novel therapeutic options.

$\dagger$ Contributed equally to this work

*Corresponding author (email: ickang@ hoseo.edu)
Angiogenesis is a complex process that involves the proliferation and migration of endothelial cells. It is delicately controlled by a variety of inducers and inhibitors that respectively cause the up- and down-regulation of angiogenesis $[3,4]$. It has been reported that most actively-studied basic fibroblast growth factors (bFGFs) and vascular endothelial growth factors (VEGFs) work as angiogenic inducers for both in vivo and in vitro growth [5-7]. Many kinds of angiogenic inhibitors have already been discovered including angiostatin, which decreases bFGF- and VEGF-mediated activation of MAPK in endothelial cells leading to inhibition of proliferation and induction of apoptosis [8]. Furthermore, Soamsan, a traditional Korean medicinal extract of herbal materials, has been shown to have anti-angiogenic 
effects and has been used to treat cardiovascular diseases [9]. Therapeutic inhibitors have been found using ProteoChip-based library screening methods. For instance, the A5-1 peptide that is effective as an angiogenesis inhibitor against integrin $\alpha 5 \beta 1$ [10], and certain Korean medicinal plant extracts chosen under the same methodology have been verified to possess anti-angiogenic functions [11], have been identified using this methodology.

HangAmDan (HAD) is composed of nine products from species of Korean medicinal plants and animals (Table 1), and has been used for the treatment of cancer patients in oriental medicine. We have investigated how the water extract of HAD (WEHAD) inhibits bFGF-induced angiogenesis using assays to measure the proliferation, migration, and adhesion of human umbilical vein endothelial cells (HUVECs) in vitro, and an ex vivo chorioallantoic membrane (CAM) angiogenesis assay.

\section{Materials and methods}

\subsection{Preparation of water extract of HAD}

HAD was provided by the East-West Cancer Center of the Dunsan Oriental Medical Hospital of Daejeon University (Daejeon, Korea) (Table 1). The WEHAD was prepared by extracting HAD powder with $1 \mathrm{~g}$ of powder in $10 \mathrm{~mL}$ of distilled water at room temperature for $24 \mathrm{~h}$. The extract was centrifuged at $1000 \times g$ for $30 \mathrm{~min}$ and then filtered and lyophilized. The extract powder was dissolved directly in distilled water.

\subsection{Cell culture}

Human umbilical vein endothelial cells (HUVECs) were provided from Innopharmascreen Inc. (Asan, Korea). Cells were cultured in a complete M199 medium (Invitrogen, CA, USA). The cells at passages 3-6 were used. HUVEC cultures were kept maintained routinely at $37^{\circ} \mathrm{C}$ in a humidified atmosphere of $5 \% \mathrm{CO}_{2}$, and used for assay at passages 3-6.

Table 1 Ingredients of HAD

\begin{tabular}{cc}
\hline Scientific name & Relative amount $(\mathrm{mg})$ \\
\hline Coix lachryma Semen & 259.0 \\
Panax notoginseng Radix & 86.0 \\
Hippocampus kelloggi & 26.0 \\
Cordyceps Militaris & 26.0 \\
Santsigu Tuber & 26.0 \\
Ginseng Radix & 26.0 \\
Bovis Calculus & 17.0 \\
Margarita & 17.0 \\
Moschus & 17.0 \\
\hline Total amount (one capsule) & 500.0 \\
\hline
\end{tabular}

\subsection{In vitro HUVEC proliferation assay}

Assessment of cell proliferation was performed according to the MTT (3-(4,5-dimethylthiazol-2-yl)-2,5-diphenyl-2H-tetrazolium bromide) assay protocol. HUVECs $\left(1 \times 10^{4}\right.$ cells/ well) were added to 96-well tissue culture plates coated with gelatin and allowed to adhere overnight. The cells were treated with extract in the presence or absence of bFGF and incubated for $72 \mathrm{~h}$. Then, $50 \mu \mathrm{L}$ of a $1 \mathrm{mg} \mathrm{mL}^{-1}$ MTT solution was added to each well, and the cells were incubated for $2 \mathrm{~h}$ at $37^{\circ} \mathrm{C}$. After the supernatants were discarded, residual formazan crystals were dissolved in $100 \mu \mathrm{L}$ of DMSO. Absorbance was measured at $595 \mathrm{~nm}$ on an ELISA plate reader (Emax, Molecular Devices, USA). GRGDSP (PEPTRON, Daejeon, Korea), a synthetic peptide, is the peptide including Arg-Gly-Asp (RGD) in which the motif acts as various integrin-recognition motifs. It is extensively used as inhibitors of integrin-ligand interactions as well as in the study on cell adhesion, migration, growth and differentiation [12]. On the other hand, GRGESP (PEPTRON, Daejeon, Korea) is the peptide which loses the function of RGD by changing Asp of motif of RGD into Glu. It is also used as a control group along with RGD. The presented data were measured in triplicate.

\subsection{In vitro HUVEC adhesion assay}

An adhesion substrate was prepared by adding $100 \mu \mathrm{L}$ of vitronectin $\left(10 \mu \mathrm{g} \mathrm{mL}^{-1}\right.$; Sigma, St. Louis, USA) diluted in phosphate-buffered saline (PBS; pH 7.3) to 96-well ELISA plates (Nunc) overnight at $4^{\circ} \mathrm{C}$. Each well was then washed twice with PBS to remove unbound vitronectin and blocked for $30 \mathrm{~min}$ at $37^{\circ} \mathrm{C}$ with $0.1 \%$ bovine serum albumin (BSA) in PBS. After blocking, the wells were washed three times with PBS.

HUVECs $\left(5 \times 10^{5}\right.$ cells $\left.\mathrm{mL}^{-1}\right)$ were added to each well of a 96-well plate coated with fibronectin. HUVEC suspension $(100 \mu \mathrm{L})$ including either fresh media (negative control) or WEHAD (30-1000 $\mu \mathrm{g} \mathrm{mL}^{-1}$ ) and bFGF $\left(5 \mathrm{ng} \mathrm{mL}^{-1}\right.$ ) was added to three wells and incubated for $90 \mathrm{~min}$ at $37^{\circ} \mathrm{C}$. After incubation, unbound cells were removed by rinsing each well twice with PBS and incubated for $1 \mathrm{~h}$ at $37^{\circ} \mathrm{C}$ with $100 \mu \mathrm{L} 1 \%$ Coomassie blue solution (v/v) that diluted with $\mathrm{MeOH}$. The optical density $(A)$ at $595 \mathrm{~nm}$ of each well was measured using a spectrophotometer (Emax, Molecular Devices, USA). The presented data were measured in triplicate.

\section{5 vitro HUVEC migration assay}

A migration assay was performed as previously [13,14]. HUVECs were placed in a modified Boyden chamber (48-well chemotaxis chamber AP48; Neuro Probe, Gaithersburg, MD, USA). Polycarbonate membranes ( $8 \mu \mathrm{m}$ pore, 
$25 \mathrm{~mm} \times 80 \mathrm{~mm}$ in size, polyvinylpyrrolidine-free; Neuro Probe) were coated with gelatin and incubated overnight at $37^{\circ} \mathrm{C}$. Basic FGF $\left(5 \mathrm{ng} \mathrm{mL}{ }^{-1}\right.$ ) in $\mathrm{M} 199$ was added to the lower chamber, and cell suspension containing $1 \times 10^{4}$ cells per $50 \mu \mathrm{L}$ media and supplemented with the indicated concentration of medicinal extracts was added to the upper chamber of each well. The chamber was incubated for $8 \mathrm{~h}$ at $37^{\circ} \mathrm{C}$ with $5 \% \mathrm{CO}_{2}$ to allow cells to migrate through the gelatin-coated polycarbonate membrane. Non-migrating cells on the upper surface of the membrane were removed with a wiper tool (Neuro Probe), and the membrane was then stained with Diff-Quik (VWR Scientific Products, Bridgeport, NJ, USA). The total number per well of migrating cells with nuclei was determined as described. The evaluated data showed the relative cell migration, which is a percentage compared with the mean cell number for each stained field. The presented data were measured in triplicate.

\subsection{In vitro capillary tube formation}

Capillary tube formation of HUVECs was performed as described with some modification [15]. Twenty four-well culture plates were coated with $250 \mu \mathrm{L}$ of Matrigel and allowed to solidify at $37^{\circ} \mathrm{C}$ for $30 \mathrm{~min}$. HUVECs $\left(2 \times 10^{5}\right.$ cells $)$ were added to each of three wells in $100 \mu \mathrm{L}$ of media containing WEHAD and bFGF of $5 \mathrm{ng} \mathrm{mL}^{-1}$ (or fresh media as a negative control). After $18 \mathrm{~h}$ of incubation, the capillary tubes were fixed, stained with a Diff-Quick solution (Becton Dickinson, San Jose, CA, USA) and observed under a phase-contrast microscope.

\subsection{Ex vivo bFGF-induced CAM angiogenesis}

An ex vivo CAM assay was performed as previously described [16,17]. Fertilized eggs were incubated at $37^{\circ} \mathrm{C}$ in humidified air. Ovalbumin $(4-5 \mathrm{~mL})$ was extracted from the bottom of the eggs using a syringe on day 3 , and windows were made within the tops of the eggs. The windows were sealed with transparent tape, and the eggs were further incubated until day 9. Thermonox (Nunc, Naperville, IL) containing bFGF (200 ng) or bFGF plus extract was implanted onto the CAM of an individual embryo. After a $48 \mathrm{~h}$ incubation period, intralipose (a white fat emulsion solution) was injected into the CAM for clear visualization of blood vessel formation, and each CAM was observed under a microscope and photographed.

\subsection{Protein expression profiling in WEHAD-treated HUVEC}

\subsubsection{Preparation of cell lysates}

When HUVECs reached confluence, they were serumstarved by incubation in M199 containing 1\% FBS for $8 \mathrm{~h}$. The cells were treated with or without WEHAD in the presence of growth factor. After $24 \mathrm{~h}$ incubation, the cells were washed twice with PBS and harvested in $5 \mathrm{mmol} \mathrm{L}^{-1}$ EDTA-PBS. The harvested cells were then maintained on ice for $10 \mathrm{~min}$ and centrifuged for $5 \mathrm{~min}$ at $1300 \mathrm{r} \mathrm{min}^{-1}$. The pellets were washed with PBS and re-centrifuged.

\subsubsection{Protein extraction and labeling}

HUVECs were extracted with Lysis-M ${ }^{\mathrm{TM}}$ (Roche, Germany) mammalian cell extraction buffer. Each protein extract (100 $\mu \mathrm{g}, 1 \mathrm{mg} \mathrm{mL}{ }^{-1}$ ) was labeled with both $\mathrm{Cy} 3$ and $\mathrm{Cy} 5$ (GE Healthcare, UK) as per the manufacturer's instructions. Free dyes were removed with SigmaSpin columns (S5059, Sigma, USA) and purified samples were stored at $4{ }^{\circ} \mathrm{C}$ until use.

\subsubsection{Preparation of antibody microarrays}

Forty-eight distinct antibodies against proteins involved in cell proliferation (Hypromatrix, Worcester, MA, USA) were spotted onto ProteoChip arrays in duplicate. The detailed procedure of array analysis has been previously described [18].

\subsubsection{Hybridization}

The fluorescence-labeled cell lysates were applied onto the antibody array and incubated for $1 \mathrm{~h}$ at $37^{\circ} \mathrm{C}$ in the dark. The slides were washed three times with PBST, $\mathrm{N}_{2}$-dried and analyzed using a fluorescence microarray scanner.

\subsubsection{Detection and data analysis}

The antibody array slides were scanned using a GenePix 4100A microarray scanner (Axon Instruments, Union City, CA, USA) with 532 and $635 \mathrm{~nm}$ lasers. Image analysis was performed for each spot using the manufacturer's software package (GenePix 6.0, Axon Instruments). The INR (internally normalized ratio) of all spots were calculated as previously described [19].

\subsubsection{Western-blot analysis}

The cell pellets were lysed using Complete Lysis M (Roche). Protease and phosphatase inhibitor cocktails (both from Roche) were added. Protein extracts $(50 \mu \mathrm{g})$ were separated on a $12 \%$ Bis-Tris Nupage gel (Invitrogen) and transferred onto a PVDF membrane. The membrane was blocked with $5 \%$ non-fat milk, or BSA in PBS (pH 7.4) containing $0.5 \%$ Tween-20. It was then incubated with rabbit anti-FAK (1:1000 dilution), rabbit anti-Rad51 (1:1000 dilution), rabbit anti-p73 (1:1000 dilution), or rabbit anti-GAPDH (1:500 dilution) for $16 \mathrm{~h}$ at $4^{\circ} \mathrm{C}$. The membrane was subsequently incubated with horseradish peroxidase-conjugated anti-rabbit secondary antibodies for $60 \mathrm{~min}$ at room temperature. Protein bands were visualized on a medical X-ray film (Agfa) using an enhanced chemiluminescence $\left(\mathrm{ECL}^{\mathrm{TM}}\right)$ kit (Invitrogen). 


\section{Results and discussion}

\subsection{Biological characterization of WEHAD effects on bFGF-induced HUVECs}

To investigate the biological activities of WEHAD, we performed proliferation, migration, and adhesion assays using HUVECs. As an antagonistic extract, WEHAD markedly inhibited the proliferation of HUVECs compared with the PBS-treated control group (Figure 1A). A half-maximal inhibition of proliferation on the endothelial cells by WEHAD was observed at a concentration of $253 \mu \mathrm{g} \mathrm{mL}^{-1}$.

To confirm the anti-angiogenic functions of WEHAD, an in vitro $\mathrm{HUVEC}$ adhesion assay and a migration assay were employed. WEHAD suppressed bFGF-induced cell attachment in a dose-dependent manner (Figure 1B). The antiadhesive efficacy of WEHAD was higher than that of RGD.
WEHAD also prevented bFGF-induced cell migration in a dose-dependent manner compared with the PBS control group (Figure 1C). To further assess the inhibitory effects of the antagonistic extracts on HUVEC proliferation, we carried out an in vitro capillary tube formation assay, and ex vivo CAM angiogenesis. Cells plated on Matrigel were treated for $16 \mathrm{~h}$ with WEHAD in the presence of bFGF and tube formation was observed using phase-contrast microscopy. WEHAD significantly suppressed tube formation at a concentration of $10 \mu \mathrm{g} \mathrm{mL}^{-1}$ (Figure 2A). The area of CAM below the disks without any treatment showed a normal density and branching pattern of the blood vessels, indicating that disk weight did not affect their growth. By contrast, the vascular branches of CAM treated with WEHAD $(10 \mu \mathrm{g} /$ egg) for $48 \mathrm{~h}$ were perturbed (Figure 2B). These findings are consistent with data obtained from HUVEC proliferation, adhesion, migration, and tubular network formation
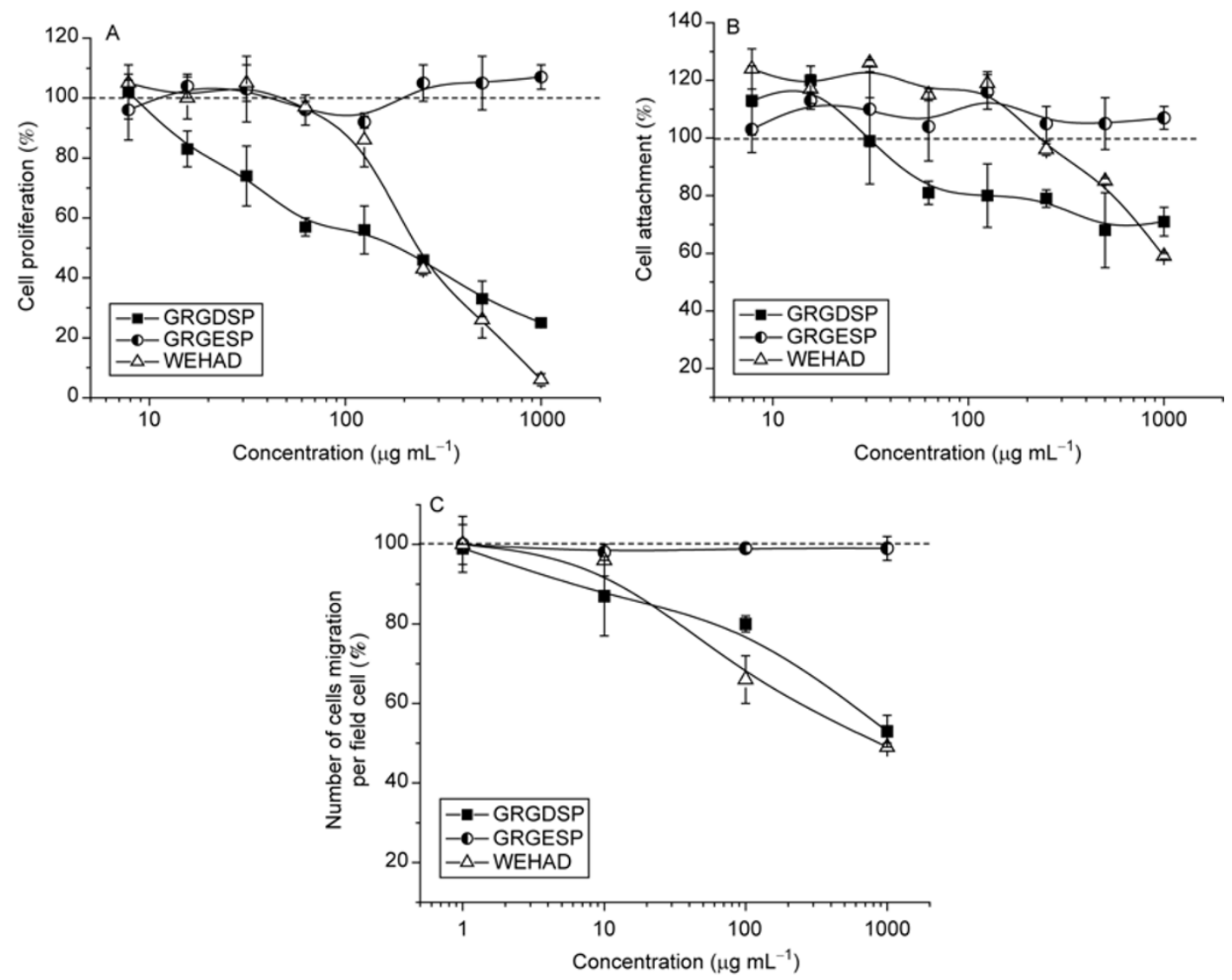

Figure 1 Inhibitory effect of WEHAD on HUVECs. A, Cell proliferation. HUVECs were incubated with different concentrations $\left(7-1000 \mu \mathrm{g} \mathrm{mL}^{-1}\right)$ of WEHAD for $72 \mathrm{~h}$ in the presence of bFGF $\left(5 \mathrm{ng} \mathrm{mL} \mathrm{mL}^{-1}\right)$. After incubation, unbound cells were removed with PBS and incubated for $2 \mathrm{~h}$ with $100 \mu \mathrm{L}$ of an MTT solution. Absorbance was measured at $595 \mathrm{~nm}$ using an ELISA reader. Control cells were incubated in the absence of bFGF and WEHAD, whereas bFGF-control cells were incubated in the presence of bFGF alone (dotted line). B, Attachment. HUVECs were incubated with different concentrations (30-1000 $\left.\mu \mathrm{g} \mathrm{mL}^{-1}\right)$ of WEHAD for $90 \mathrm{~min}$ in the presence of bFGF $\left(5 \mathrm{ng} \mathrm{mL} \mathrm{mL}^{-1}\right)$ on fibronectin-coated 96-well ELISA plates. After incubation, unbound cells were removed with PBS, and attached cells were fixed with methanol and stained with crystal violet. C, Migration. Dose-dependent inhibition of bFGF-induced HUVEC migration by WEHAD was examined. The total number of cells per field ( $Y$-axis) was measured using an Image Gauge V2.54 program. Control cells were incubated in the absence of bFGF and WEHAD, whereas bFGF-control cells were incubated in the presence of bFGF alone (dotted line). GRGDSP and GRGESP were used as a positive and a negative control, respectively. 

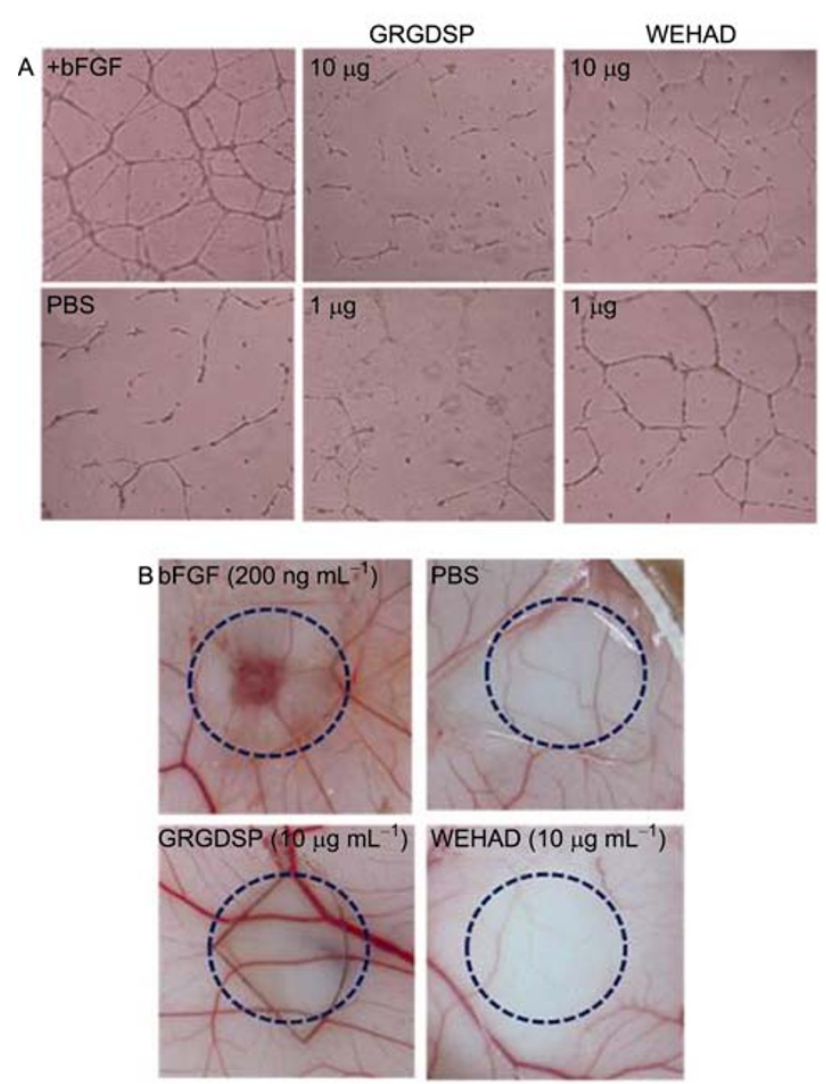

\begin{tabular}{|c|c|c|}
\hline & $\begin{array}{c}\text { Number of } \\
\text { anti-angiogenic } \\
\text { CAMs }\end{array}$ & $\begin{array}{c}\text { CAM angio- } \\
\text { genesis } \\
\text { inhibition (\%) }\end{array}$ \\
\hline bFGF & $0 / 10$ & 0 \\
\hline PBS control & $1 / 10$ & 10 \\
\hline GRGDSP & $9 / 10$ & 90 \\
\hline WEHAD & $9 / 10$ & 90 \\
\hline
\end{tabular}

Figure 2 Inhibitory effects of WEHAD on capillary tube formation and bFGF-induced CAM angiogenesis. A, HUVECs were seeded on Matrigel-coated 24-well plates in serum-free media containing GRGDSP or WEHAD in the presence of bFGF $\left(5 \mathrm{ng} \mathrm{mL}^{-1}\right)$ or PBS alone. After $18 \mathrm{~h}$, the capillary tubular network was stained with a Diff-Quick solution (Becton Dickinson, San Jose, CA, USA) and observed under a phase-contrast microscope. B, Thermonox discs containing bFGF alone, RGD (10 $\mu \mathrm{g} / \mathrm{egg})$, and WEHAD $(10 \mu \mathrm{g} / \mathrm{egg})$ in the presence of bFGF (200 ng/egg) were tested on each of 10 CAMs on nine-day-old chick embryos. After a $48 \mathrm{~h}$ incubation period, the CAMs were observed. A negative control was incu-

bated in the absence of bFGF. GRGDSP was used as a positive control.

assays. Collectively, these results suggest that WEHAD could be useful for the development of a potent angiogenesis inhibitor.

\subsection{Expression profiling of cell cycle proteins in WEHAD-treated HUVECs using antibody microarray}

The goal of this study was to analyze the expression pattern of endogenous signaling proteins in HUVECs treated with
WEHAD. To investigate the protein expression profile in WEHAD-treated HUVECs, an antibody microarray constructed on ProteoChip was used. To carry out the antibody microarray analysis, WEHAD-treated HUVECs were labeled with $\mathrm{Cy} 3$ and $\mathrm{Cy} 5$.

Antibody microarray analysis of WEHAD-treated HUVECs labeled with Cy5 compared with the Cy3-labeled untreated HUVECs revealed up- or down-regulation of different proteins (Figure 3A and B). A further attempt was made to validate the antibody microarray data by immunoblot analysis. Selected up-regulated proteins such as RAD51, Cyclin B1, and p73 showed increased expression, whereas down-regulated proteins such as FAK showed a decrease in protein amount in Western blotting analyses (Figure 3C).

Focal adhesion kinase (FAK) is a widely expressed cytoplasmic protein tyrosine kinase involved in integrin-mediated signal transduction. It plays an important role in the control of several biological processes including cell spreading, migration, and survival [20]. Our antibody array data indicate that the inhibitory effect of WEHAD on the proliferation of HUVECs may be partly due to the decreased expression of FAK involved in integrin-mediated cell survival. p73, a member of the p53 family, is involved in cell cycle regulation, and induction of apoptosis. The p73-induced apoptosis is mediated by endoplasmic reticulum stress and induction of p53 up-regulated modulator of apoptosis (PUMA) [21,22]. Our finding suggests that the inhibition of HUVEC proliferation by WEHAD may be mediated by induction of apoptosis in the cells via increased p73 expression. It was reported that enhancement of p53 ubiquitination by the FAK FERM domain promotes cell proliferation and cell survival [23]. Based on our antibody array data, WEHAD treatment of HUVECs caused down-regulation of FAK as well as up-regulation of $\mathrm{p} 73$, resulting in suppression of cell proliferation. Additionally, the DNA repair protein, RAD51, was regulated by WEHAD in HUVECs. Collectively, these data suggest that WEHAD significantly inhibits bFGF-induced angiogenesis through the regulation of expression of certain proteins involved in cell growth.

In this study, we observed anti-angiogenic effects of WEHAD in HUVECs through different angiogenesis assays induced by bFGF. WEHAD had dose-dependent inhibitory effects on proliferation, migration and adhesion (Figure 1). We also verified this inhibitory effect through an ex vivo CAM assay (Figure 2B). Thus, WEHAD may have a potential therapeutic utility in the treatment of cancers involving neovascularization. However, as we already described, WEHAD is a natural product made up of nine types of plants and animals, i.e., it contains many types of compounds. Thus, further attempts will be made to examine the molecular mechanism correlated with cellular signaling pathways, and to identify the active compounds that appear to create the anti-angiogenic effects of WEHAD. 

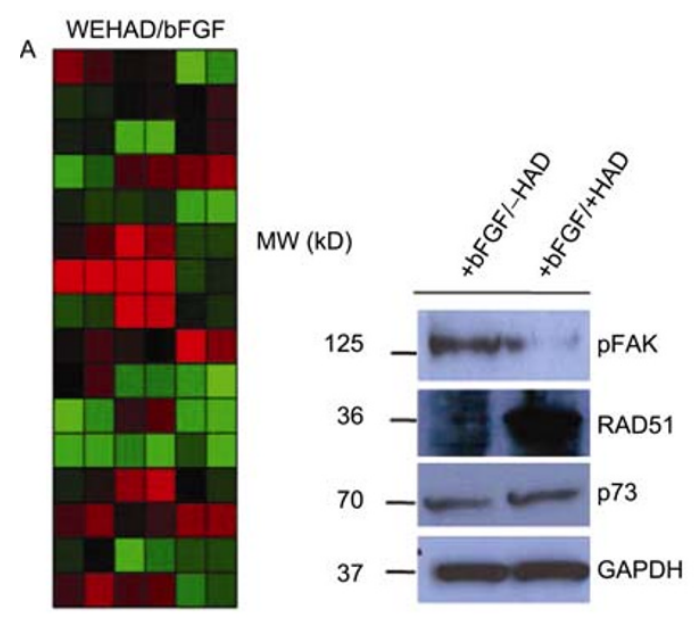

\begin{tabular}{|c|c|c|}
\hline Raf-1 & ERK2 & pFAK \\
\hline pERK1/2 & MEK-1 & MEK kinase-1 \\
\hline H-Ras & FAK & XRCC4 \\
\hline PIK & ERK1 & IKB-b \\
\hline Cyclin E & BRCA1 & P16 \\
\hline P63 & P73 & C-MOS \\
\hline RAD51 & RAD52 & CHK1 kinase \\
\hline GADD45 $\gamma$ & DMC1 & p53 \\
\hline Cip1/WAF-1/p21 & PCNA & Cyclin B1 \\
\hline E2F-1 & p35 & Cdc6 \\
\hline Cdk2 & Nibrin/Nbs1 & Cullin-1 \\
\hline BRCA2 & Cdc25A & Cyclin D \\
\hline Cyclin A & Cdk4 & Cdk1/cdc2 \\
\hline NFkBp52 & Kip1 (p27) & STAT1 \\
\hline Kip2 & STAT3 & Rb2 \\
\hline pSTAT1 & Sam 68 & GAPDH \\
\hline
\end{tabular}

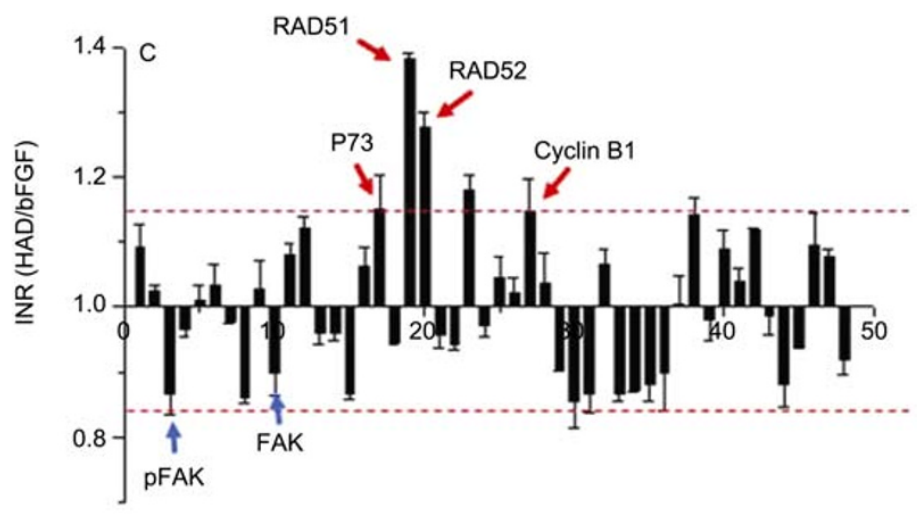

Antibodies

Figure 3 Analysis of differential expression of cell cycle proteins in HUVECs treated with WEHAD using the antibody microarray. A, Graded virtual image of Cy5:Cy3 ratios at spots within arrays of protein extracts from WEHAD-treated HUVECs and validation of antibody microarray data by immunoblot analysis. B, Map of the antibody chip. Up- and down-regulated proteins are shown by red and blue, respectively. C, Graphical representation of Cy5:Cy3 ratios on the antibody arrays. The bar chart shows the mean fluorescent intensity of three spots plotted over three independent experiments. Proteins having a normal median ratio in the range of 1.0 were considered as unchanged expression.

1 Folkman J, Shing Y. Angiogenesis. J Biol Chem, 1991, 267: 1093110934

2 Folkman J. Angiogenesis in cancer, vascular, rheumatoid and other diseases. Nat Med, 1995, 1: 27-31

3 Fan T P, Jaggar R, Bicknell R. Controlling the vasculature: Angiogenesis, anti-angiogenesis and vascular targeting of gene therapy. TiPS, 1995, 16: 57-66

4 Blussolino F, Mantovani A, Persico G. Molecular mechanisms of blood vessel formation. Trends Biochem Sci, 1997, 22: 251-256

5 Redlitz A, Daum G, Sage E H. Angiostatin diminishes activation of the mitogen-activated protein kinases ERK-1 and ERK-2 in human dermal microvascular endothelial cells. J Vasc Res, 1999, 36: 28-34

6 Teruyama K, Abe M, Nakano T, et al. Role of transcription factor Ets-1 in the apoptosis of human vascular endothelial cells. J Cell Physiol, 2001, 188: 243-252

7 Segura I, Serrano A, De Buitrago G G, et al. Inhibition of programmed cell death impairs in vitro vascular-like structure formation and reduces in vivo angiogenesis. FASEB J, 2002, 16: 833-841

8 Chen Y H, Wu H L, Chen C K, et al. Angiostatin antagonizes the action of VEGF-A in human endothelial cells via two distinct pathways.
Biochem Biophys Res Commun, 2003, 310: 804-810

9 Yoon S C, Kim J K, Kwak D H, et al. Antitumor activity of Soamsan, a traditional Korean medicine, via suppressing angiogenesis and growth factor transcription. J Ethnopharmacol, 2004, 93: 403-408

10 Kim E Y, Bang J Y, Chang S I, et al. A novel integrin $\alpha 5 \beta 1$ antagonistic peptide, A5-1, screened by Protein Chip system as a potent angiogenesis inhibitor. Biochem Biophys Res Commun, 2008, 377: 1288-1293

11 Bang J Y, Kim E Y, Seong N S, et al. ProteoChip-based libraryscreening of integrin $\alpha 5 \beta 1$ antagonists from Korean medicinal plant extracts. Arch Pharm Res, 2007, 30: 1584-1589

12 Aguzzi M S, Giampietri C, De Marchis F, et al. RGDS peptide induces caspase 8 and caspase 9 activation in human endothelial cells. Blood, 2004, 103: 4180-4187

13 Wickström S A, Alitalo K, Keski-Oja J. An endostatin-derived peptide interacts with integrins and regulates actin cytoskeleton and migration of endothelial cells. J Biol Chem, 2004, 279: 20178-20185

14 Cattaneo M G, Pola S, Francescato P, et al. Human endostatin-derived synthetic peptides possess potent antiangiogenic properties in vitro and in vivo. Exp Cell Res, 2003, 283: 230-236 
15 Brooks P C, Montgomery A M, Rosenfeld M, et al. Integrin $\alpha v \beta 3$ antagonists promote tumor regression by inducing apoptosis of angiogenic blood vessels. Cell, 1994, 79: 1157-1164

16 Ferguson T A, Mizutani H, Kupper T S. Two integrin-binding peptides abrogate $\mathrm{T}$ cell-mediated immune responses in vivo. Proc Natl Acad Sci USA, 1991, 88: 8072-8076

17 Hamburger V. A Manual of Experimental Embryology. Rev. ed. Chicago: University of Chicago Press, 1960. 143-173

18 Ahn E H, Kang D K, Chang S I, et al. Profiling of differential protein expression in angiogenin-induced HUVECs using antibody-arrayed ProteoChip. Proteomics, 2006, 6: 1104-1109

19 Andersson O, Kozlowski M, Garachtchenko T, et al. Determination of relative protein abundance by internally normalized ratio algorithm with antibody arrays. J Proteome Res, 2005, 4: 758-767

20 Parsons J T, Martin K H, Slack J K, et al. Focal adhesion kinase: A regulator of focal adhesion dynamics and cell movement. Oncogene, 2000, 19: 5606-5613

21 Ramadan S, Terrinoni A, Catani M V, et al. p73 induces apoptosis by different mechanisms. Biochem Biophys Res Commun, 2005, 331: 713-717

22 Vilgelm A, El-Rifai W, Zaika A. Therapeutic prospects for p73 and p63: Rising from the shadow of p53. Drug Resist Updat, 2008, 11: 152-163

23 Lim S T, Chen X L, Lim Y, et al. Nuclear FAK promotes cell proliferation and survival through FERM enhanced p53 degradation. Mol Cell, 2008, 29: 9-22

Open Access This article is distributed under the terms of the Creative Commons Attribution License which permits any use, distribution, and reproduction in any medium, provided the original author(s) and source are credited. 